\title{
MRSA and cataract surgery - reflections for practice
}

This article was published in the following Dove Press journal:

Clinical Ophthalmology

14 October 2010

Number of times this article has been viewed

\section{LF Porter \\ RU Khan ${ }^{2}$ \\ A Hannan ${ }^{3}$ \\ SP Kelly'}

'Royal Bolton Hospital NHS Foundation Trust, Bolton, UK; ${ }^{2}$ Departments of Microbiology, Royal Bolton Hospital NHS Foundation Trust, Bolton, UK;

${ }^{3}$ Haughton Thornley Medical Centers, NHS Tameside and Glossop, UK
Correspondence: Dr Louise F Porter Royal Bolton Hospital NHS Foundation Trust, Minerva Road, Bolton, BL4 OJR UK Tel +44 I204390694

Email louise.porter@postgrad.man.ac.uk
Introduction: Postoperative bacterial endophthalmitis is a devastating complication of cataract surgery. Methicillin-resistant Staphylococcus aureus (MRSA) endophthalmitis is rare. Recent debate over MRSA screening in United Kingdom (UK) National Health Service (NHS) hospital services has implications for cataract patients and ophthalmology services.

Aims: To discuss issues for clinical practice as based on reflective experience at a UK district general NHS hospital in relation to care of MRSA-positive cataract patients.

Methods: Retrospective case series and reflective practice.

Results: Three cases presented highlight practice points around cataract patients colonized with MRSA. Known or determined MRSA-colonized patients should be treated with anti-microbial agents at time of cataract surgery known to be active against MRSA. Preventative treatment with intracameral vancomycin or intravenous teicoplanin alongside appropriate topical treatments may be of merit. Importantly fluoroquinolones, often prescribed by cataract surgeons, may have a selective effect favoring the proliferation of MRSA.

Conclusion: MRSA screening may cause unnecessary delays in cataract care and may represent a patient safety concern in its own right. Patients colonized with MRSA may safely undergo cataract surgery provided there is no evidence of periorbital infection and provided appropriate infection control and antibiotic prophylaxis measures are used. The well-prepared cataract surgeon needs to be aware of developments in infection control and should liaise with local clinical microbiology colleagues in relation to bacterial resistance to antibiotics.

Keywords: methicillin-resistant Staphylococcus aureus (MRSA), endophthalmitis, screening

\section{Introduction}

Postoperative endophthalmitis is an uncommon but devastating complication of cataract surgery with reported rates of between $0.06 \%$ and $0.25 \% .{ }^{1}$ Incidence rates of methicillin-resistant Staphylococcus aureus (MRSA) endophthalmitis are poorly defined, but there are recent reports of clusters of such cases leading to discussion. ${ }^{2,3}$ Screening and management policies for MRSA carriers in cataract care in the UK are variable. ${ }^{4}$ Three patients treated for cataract at our hospital, and who were colonized with MRSA, serve to highlight practice points around the care of such patients. Relevant issues are reflected upon.

\section{Case I}

A 70-year-old female was referred by her general practitioner (GP) with dense cataract in the right eye and proliferative diabetic retinopathy in the left eye. Visual acuity was 
1/60 in the right eye and 6/60 in the left eye. Co-morbidities included congestive cardiac failure, peripheral vascular disease, chronic obstructive pulmonary disease, chronic kidney disease, eczema, insulin-dependent diabetes mellitus, and previous pulmonary embolus. She lived alone and smoked 20 cigarettes daily. Her GP had approached us as he was concerned that the patient had been denied ophthalmic surgery for several years at 2 nearby ophthalmic institutions solely due to her MRSA colonization and despite failed MRSA eradication regimens. The patient was house-bound because of her severe visual impairment. Uneventful day care phacoemulsification cataract surgery was performed in our department under local anesthesia through a clear corneal incision following a course of attempted MRSA eradication treatment with nasal mupirocin and chlorhexidine baths to satisfy infection control policy. The patient was deliberately not re-swabbed prior to cataract surgery. Infection control measures included provision of a single room and placement last on the operating list. Povodineiodine periocular and conjunctival sac disinfection was used during the surgery and subconjunctival cefadrine was injected at the end of the procedure. Peri-operatively the patient was given $400 \mathrm{mg}$ of teicoplanin by intravenous bolus injection. Post-operative antibiotic regimen consisted of levofloxacin drops 4 times a day for 4 weeks. Visual acuity recovered to 6/60 due to co-existent diabetic maculopathy previously masked by the severe lens opacity.

\section{Case 2}

A 72-year-old male in residential nursing home care presented with advanced cataracts and visual loss. This patient was a known to be colonized with MRSA. Attempted MRSA eradication regimen consisting of nasal mupirocin and chlorhexidine baths was implemented for 5 days prior to surgery, and infection control measures included provision of a single room and placement last on the operating list. Povodine-iodine periocular and conjunctival sac disinfection was used. Uneventful sutureless phacoemulsification cataract surgery was undertaken as a day case. Subconjunctival cefadrine was injected at the end of the procedure. Post-operative prescriptions included tobramycin/dexamethasone drops 4 times daily for 1 month and ofloxacin drops 4 times daily for 1 week. The postoperative visual acuity was 6/9. Mild anterior uveitis was present 2-weeks postoperatively which settled spontaneously on the topical steroid regimen prescribed. No evidence of infection was encountered. The patient later underwent successful day case left cataract surgery with implementation of the same pre- and peri-operative measures. Post-operative visual acuity in the left eye improved to $6 / 18$.

\section{Case 3}

An 88-year-old lady with active MRSA-infected chronic leg ulcers was referred with advanced vision loss, counting fingers in the right eye and 3/60 in the left eye. Significant cataracts were present, with co-existent dry age-related macular degeneration (AMD) in the right eye and neovascular AMD in the left eye. The patient was listed for left cataract surgery and a course of intravitreal ranibizumab as a day case. Infection control measures included provision of a single room and placement last on the operating list. Pre-operatively the patient was prescribed levofloxacin drops 4 times daily for 4 days, and povodine-iodine periocular and conjunctival sac disinfection was applied prior to surgery. Peri-operatively the patient was given intravenous teicoplanin $400 \mathrm{mg}$ bolus. She underwent phacoemulsification surgery and intravitreal ranibizumab injection in her left eye at the same session. Subconjunctival cephradine was injected at completion of surgery followed by levofloxacin drops 2 hourly for 2 days and then 4 hourly for 5 days along with prednisolone $0.5 \%$ drops 4 times daily for 4 weeks. The visual acuity improved to $6 / 24$. The macular edema from wet AMD resolved.

\section{Discussion}

We report 3 patients with MRSA-colonization and advanced visual loss who successfully underwent cataract surgery and which illustrate several practice points. Firstly, the unproven benefits of screening for MRSA in cataract patients may be outweighed by treatment delays and harm to the patient. Secondly, patients colonized with MRSA infection may safely undergo cataract surgery provided that the appropriate pre peri- and post-operative infection control measures and adequate antibiotic prophylaxis are used.

There has been debate over the role of MRSA screening in ophthalmology. In late 2006 the UK Department of Health recommended that all elective admissions in England should be screened for MRSA and if found positive should then undergo decolonization regime. ${ }^{5}$ Following comments by the Royal College of Ophthalmologists and others, it was clarified in refreshed operational guidance to the National Health Service (NHS) in early 2008 that day-case ophthalmology patients in the English NHS did not have to undergo routine MRSA screening. ${ }^{6,7}$ A survey of UK ophthalmology departments undertaken in September 2005 demonstrated significant variability surrounding local MRSA screening practices. ${ }^{4}$ Following a consideration of available evidence The MRSA Screening Pathfinder Programme in Scotland has not recommended universal MRSA screening requirements in its Interim Report. ${ }^{8}$ MRSA screening is not currently required 
in England or Scotland for day-care ophthalmology patients, but is required for admitted ophthalmic patients. ${ }^{7,9}$

Given the large numbers of cataract surgeries undertaken in many developed economies the logistics and resource implications of screening such large numbers of patients for MRSA carrier status and subsequent decolonization are not insignificant. Furthermore it is possible that delays imposed by MRSA screening diktats and repeated decolonization regimens may be an added unintended patient safety concern as our Case 1 demonstrates. Of relevance, the delays in Case 1 occurred during the period in 2006-2008 when MRSA screening policy in ophthalmic departments in some NHS Trusts were perhaps in states of transition. In addition, such MRSA screening and eradication policies may have little bearing on ophthalmic clinical outcomes. We are unaware of any studies that demonstrate a reduced risk of endophthalmitis in the presence of MRSA screening and eradication regimens. This is possibly due to the relative infrequency of MRSA endophthalmitis, but also possibly as MRSA colonization is commonly identified by sampling patients' anterior nares and perineal regions. Such screening sampling methods may not reflect the periocular bacterial flora relevant to cataract surgery and risk of endophthalmitis. ${ }^{10,11}$ In addition there are no proven eradication regimens, very few studies having used controls or randomization. ${ }^{12}$ Finally existing current MRSA eradication/decolonization regimes are only partially effective. Rohr et $\mathrm{al}^{13}$ reported that $64 \%$ of affected patients were cleared of MRSA colonization after a course of eradication treatment with intranasal mupirocin ointment and chlorhexidine baths, indicating such a regime was ineffective in nearly one-third of such patients. If no active periorbital infection is present on clinical examination, proceeding with cataract surgery on clinical grounds is, in our opinion, probably safe despite knowing MRSA screening status or not. Likewise postponement of cataract surgery on the day of surgery should be considered if any signs of peri-orbital infection are found to be present despite the potential disappointment to patients of cancellation on the day of surgery, and despite this being regarded as a 'negative indicator' by performance managers.

In addition, with the emergence of community acquired MRSA many MRSA-colonized patients may not have the patient risk factors required to trigger screening on hospitalization. Rao and colleagues ${ }^{14}$ screened all patients admitted through a hospital Emergency Department for MRSA carriage and demonstrated that $15.5 \%$ of the patients found to be positive for MRSA did not have recognized risk factors such as recent hospital admission, advanced age or care home residency.
Various measures have been suggested to reduce the risk of postoperative bacterial endophthalmitis, the Royal College of Ophthalmologists ${ }^{15}$ and American Academy of Ophthalmology ${ }^{16}$ recommend pre-operative conjunctival irrigation with $5 \%$ povodine iodine as prophylaxis against infection. The European Society of Cataract and Refractive Surgeons (ESCRS) Endophthalmitis Study Group investigators reported reductions in postoperative endophthalmitis incidence following cataract surgery in patients receiving intracameral cefuroxime injection in addition to povodine iodine. ${ }^{17}$ Resultantly, practice surveys show that intracameral cefuroxime injection has become increasingly popular amongst UK cataract surgeons. ${ }^{18}$ However cefuroxime is not effective against $\mathrm{MRSA}^{19}$ and as is being found in clinical practice in cases of MRSA endophthalmitis. ${ }^{20}$ Fourth-generation fluoroquinolone antimicrobial agents, such as moxifloxacin or gatifloxin, offer an alternative option for topical and intracameral antibiotic prophylaxis and are favored in practice surveys undertaken amongst many members of the American Society of Cataract and Refractive Surgeons. ${ }^{21}$ However fluoroquinolone-resistant $S$. aureus is also an emerging trend of bacterial resistance. ${ }^{22-26}$ Of potential clinical relevance to cataract surgeons favoring topical fluorquinolones, such antibiotics have also been shown to exert a strong selective pressure favoring the growth of MRSA organisms. ${ }^{27,28}$ In a recent case series of 33 cases of culture-positive postoperative endophthalmitis following cataract surgery, ${ }^{22}$ all 6 cases of MRSA endophthalmitis had received topical fluoroquinolone antibiotics (moxifloxacin, gatifloxacin or levofloxacin) 2 or 3 days prior to cataract surgery and in the postoperative period. Importantly, none of the isolated organisms in the case series from Deramo and colleagues were sensitive to any fluoroquinolone antibiotic; but all 6 organisms were sensitive in vitro to both gentamicin and vancomycin. ${ }^{22}$ These resistance patterns are also in keeping with several studies reporting in vitro bacterial resistance to the newer-generation fluoroquinolones ciprofloxacin, ofloxacin, and levofloxacin in corneal and conjunctival MRSA infections. ${ }^{23,24}$ A review of cases of postoperative endophthalmitis treated over an 11-year period at Wills Eye Hospital ${ }^{25}$ demonstrated changes over time in the in vitro susceptibility of bacteria isolated from the vitreous of patients following cataract surgery, with significant increases in resistance in such bacterial isolates to ciprofloxacin and ofloxacin. Importantly, resistance to vancomycin remained unchanged throughout the study time period in that series. While pre-operative topical antibiotic prophylaxis in cataract surgery is commonplace, it has been associated with significantly increased risk of development 
of infection in a survey from Germany. ${ }^{29}$ Sub-conjunctival antibiotic injections at completion of cataract surgery remain popular in the UK. A reduction of postoperative endophthalmitis with this approach has been demonstrated in a nested case-control study from Western Australia. ${ }^{30}$ As all MRSA organisms responsible for postoperative endophthalmitis in the cases series from Deramo et $\mathrm{al}^{22}$ were sensitive to gentamicin or vancomycin antibiotics, it may also perhaps be inferred that such antibiotics may also be of potential merit in cataract patients who are colonized with MRSA.

In conclusion, while it may be of some merit to know whether patients are colonized with MRSA or not, only patient periorbital/conjunctival colonization is likely to be clinically relevant to cataract surgeons when aiming to provide optimal outcomes for cataract surgery patients. Patients with active peri-ocular or conjunctival infection should not undergo intraocular surgery. MRSA screening and associated eradication regimes may cause unnecessary delays in some ophthalmic patients. It is reasonable, in our opinion, to treat cataract patients with known MRSA carrier status with nasal mupirocin, and to advise the recommended bathing measures as well as consider administering antibiotics known to be active against MRSA, such as gentamicin, vancomycin or teicoplanin. Fluoroquinolone antibiotics should be discouraged in this patient group. Advice from a clinical microbiologist with knowledge of current local bacterial antibiotic sensitivity patterns is of merit. In the era of both health care and community acquired MRSA infections, particular vigilance and attention to infection control is required in all cases of cataract surgery, whether or not patients have been screened for, or carry, recognized risk factors for MRSA colonization.

\section{Acknowledgments}

We gratefully acknowledge comments and suggestions from Sue Webber FRCOphth, Consultant Ophthalmologist, on a draft of our manuscript.

\section{Disclosure}

The authors disclose no conflicts of interest.

\section{References}

1. Taban M, Behrens A, Newcomb RL, et al. Acute endophthalmitis following cataract surgery: a systematic review of the literature. Arch Ophthalmol. 2005;123(5):613-620.

2. Tang HHY, Yip PP, Woo CF, Ho CK, Que TL. Methicillin-resistant Staphylococcus aureus endophthalmitis after phacoemulsificaion in a continous ambulatory peritoneal dialysis patient. $J$ Cataract Refract Surg. 2008;34:1806-1808.
3. O’Brien TP, Arshinoff A, Mah FS. Perspectives on antibiotics for postoperative endophthalmitis prophylaxis: Potential role of moxifloxacin. J Cataract Refract Surg. 2007;33:1790-1800.

4. Rathod D, Luqmani N, Webber SK, Hosein IK. Survey of meticillinresistant Staphylococcus aureus policies in UK eye departments. Journal Hosp Infection. 2009;72:314-318.

5. Department of Health. Screening for Meticillin-resistant Staphylococcus aureus (MRSA) colonisation: a strategy for NHS trusts - a summary of best practice. Department of Health, 2006. Available from: http:// www.dh.gov.uk/prod_consum_dh/groups/dh_digitalassets/@dh/@en/ documents/digitalasset/dh_063187.pdf

6. Duerden B. Inspector of Microbiology and Infection Control, the Department of Health. Letter to Royal College of Ophthalmologists. Jan 2008.

7. Beasley C, Flory D. MRSA screening - operational guidance. Gateway ref: 10324. Department of Health, 2008. http://www.dh.gov.uk/ prod_consum_dh/groups/dh_digitalassets/@dh/@en/documents/ digitalasset/dh_086682.pdf

8. Health Protection Scotland. National Services Scotland, NHS Scotland. MRSA Screening Pathfinder Programme: Interim Report. 2009. http:// www.hps.scot.nhs.uk/haiic/sshaip/mrsascreeningprogramme.aspx

9. Stewart S. MRSA Screening Programme Manager, Health Protection Scotland. Personal Communication. Feb 2010.

10. Bannerman TL, Rhoden DL, McAllister SK, Miller JM, Wilson LA. The source of coagulase-negative staphylococci in the Endophthalmitis Vitrectomy Study. A comparison of eyelid and intraocular isolates using pulsed-field gel electrophoresis. Arch Ophthalmolol. 1997;115(3):357-361.

11. Kenchappa P, Duggirala A, Ahmed N, et al. Fluorescent amplified fragment length polymorphism genotyping demonstrates the role of the biofilm producing methicillin-resistant Staphylococcus epidermidis strains in postoperative endophthalmitis. BMC Ophthalmol. 2006;6:1.

12. Tom TSM, Kruse MW, Reichman RT. Update: Methicillin resistant Staphylococcus aureus screening and decolonisation in cardiac surgery. Ann Thorac Surg. 2009;88:695-702.

13. Rohr U, Mueller C, Wilhelm M, Muhr G, Gatermann S. Methicillinresitant Staphylococcus aureus decolonisation in hospitalized patients with variable site colonisation using mupirocin in combination with ocetenidine dihydrochloride. J Hospital Infection. 2003;54: 305-309.

14. Rao GG, Michalczyk P, Nayeem N, Wlaker G, Wigmore L. Prevalence and risk factors for methicillin-resistant Staphylococcus aureus in adult emergency admissions - a case for screening all patients. $J$ Hospital Infection. 2007;66:15-21.

15. Royal College of Ophthalmologists. Cataract Surgery Guidelines. Royal College of Ophthalmologists: London, UK. 2004.

16. American Academy of Ophthalmology. Cataract in the adult eye, preferred practice pattern. San Francisco: American Academy of Ophthalmology, 2006. Available from: www.aao.org/ppp

17. ESCRS Endophthalmitis Study Group. Prophylaxis of postoperative endophthalmitis following cataract surgery: results of the ESCRS multicentre study and identification of risk factors. $J$ Cataract Refract Surg. 2007;33:978-988.

18. Daniel M. Gore, Romesh Angunawela I, Brian C. Little United Kingdom survey of antibiotic prophylaxis practice after publication of the ESCRS Endophthalmitis Study. J Cataract Refract Surg. 2009;35: 770-773.

19. Cowan MK, Talaro KP. Microbiology: A systems approach. McGrawHill Science Engineering; 2008.

20. Major JC Jr, Engelbert M, Flynn HW Jr, Miller D, Smiddy WE, Davis JL. Staphylococcus aureus endophthalmitis: antibiotic susceptibilities, methicillin resistance, and clinical outcomes. Am JOphthalmol. 2010;149(2):278-283.

21. Chang DF, Braga-Mele R, Mamalis N, et al. Prophylaxis of postoperative endophthalmitis after cataract surgery, Results of the 2007 ASCRS member survey. J Cataract Refract Surg. 2007;42:1801-1805. 
22. Deramo VA, Lai JC, Winokur J, et al. Visual outcome and bacterial sensitivity after methicillin-resistant Staphylococcus Aureus-associated acute endophthalmitis. Am J Ophthalmol. 2008;145:413-417.

23. Marangon FB, Miller D, Muallem MS, et al. Ciprofloxacin and levofloxacin resistance among methicillin-sensitive Staphylococcus aureus isolated from keratitis and conjunctivitis. Am J Ophthalmol. 2004; $137: 453-458$.

24. Goldstein MH, Kowalski RP, Gordon YJ. Emerging fluoroquinolone resistance in bacterial keratitis: a five-year review. Ophthalmology. 1999;106:1313-1318.

25. Recchia FM, Busbee BG, Pearlman RB, et al. Changing trends in the microbiologic aspects of postcataract endophthalmitis. Arch Ophthalmol. 2005;123:341-346.

26. Sanders CC, Sanders WE, Thomson KS. Fluoroquinolone resistance in staphylococci: New challenges. Eur J Clin Microbiol Infect Dis. 1995; 14 Suppl 1:S6-S11.
27. Tattevin P, Basuino L, Chambers HF. Subinhibitory fluoroquinolone exposure selects for reduced beta-lactam susceptibility in methicillinresistant Staphylococcus aureus and alteration in the SOS-mediated response. Resp Microbiol. 2009;160(3):187-192.

28. Lihara H, Suzuki T, Kawamura Y, Ohkusu K, et al. Emerging multiple mutations and high-level fluoroquinolone resistance in methicillinresistant Staphylococcus aureus isolated from ocular infections. Diagn Microbiol Infect Dis. 2006;56(3):297-303.

29. Schmitz S, Dick HB, Krummenauer F, et al. Endophthalmitis in cataract surgery: results of a German survey. Ophthalmology. 1999;106: 1869-1877.

30. Ng JQ, Morlet N, Bulsara MK, et al. Reducing the risk for endophthalmitis after cataract surgery: population-based nested case-control study: endophthalmitis population study of Western Australia sixth report J Cataract Refract Surg. 2007;33:269-280.
Clinical Ophthalmology

\section{Publish your work in this journal}

Clinical Ophthalmology is an international, peer-reviewed journal covering all subspecialties within ophthalmology. Key topics include: Optometry; Visual science; Pharmacology and drug therapy in eye diseases; Basic Sciences; Primary and Secondary eye care; Patient Safety and Quality of Care Improvements. This journal is indexed on

Submit your manuscript here: http://www.dovepress.com/clinical-ophthalmology-journal

\section{Dovepress}

PubMed Central and CAS, and is the official journal of The Society of Clinical Ophthalmology (SCO). The manuscript management system is completely online and includes a very quick and fair peer-review system, which is all easy to use. Visit http://www.dovepress.com/ testimonials.php to read real quotes from published authors. 